\title{
Working pattern of powerloom MSMEs in Ludhiana city
}

\section{Garima Singh and Kawaljit Kaur Brar}

Received: 09.10.2020; Revised: 09.11.2020; Accepted: 26.11 .2020

See end of the paper for authors' affiliations

\section{Garima Singh}

Department of Apparel and

Textile Science, Punjab

Agricultural University,

Ludhiana (Punjab) India

Email : gsingh1505@gmail.com
ABSTRACT : In the present study hyperglycemic and hyperlipedmic subjects were supplemented with fibre and polyphenol rich nutrimix. The study was designed as comparative study between residents of 2 cities i.e. Vizag and Bhubaneswar, from each city 80 participants were selected in the age group of 40-60 years. The data relating to study was collected using questionnaire method. The product was supplemented as a part of their daily diet for a period of 6 months. Post analysis the result showed decrease in blood glucose and lipid levels of the participants. A significant improvement was found in blood glucose levels of type 2 diabetic subjects.

KEY WORDS: Working pattern, Management, Production run period, Micro, Small and medium enterprises

- HOW TO CITE THIS PAPER : Singh, Garima and Brar, Kawaljit Kaur (2020). Working pattern of powerloom MSMEs in Ludhiana city. Asian J. Home Sci., 15 (2) : 376-380, DOI: 10.15740/HAS/AJHS/ 15.2/376-380. Copyright@ 2020: Hind Agri-Horticultural Society. 